\title{
Emerging evidence for non-pharmacologic interventions in reducing the burden of respiratory illnesses
}

\author{
Rutvij A. Khanolkar ${ }^{1,2}$ (]) Aleksandar Trajkovski ${ }^{3} \cdot$ Arnav Agarwal $^{4} \cdot$ Merril A. Pauls $^{5} \cdot$ Eddy S. Lang $^{1,2,6}$
}

Received: 19 November 2021 / Accepted: 15 January 2022 / Published online: 4 February 2022

(c) The Author(s), under exclusive licence to Società Italiana di Medicina Interna (SIMI) 2022

\begin{abstract}
The global pandemic caused by SARS-CoV-2 (COVID-19) has led to significant morbidity and mortality, and unprecedented economic and health system disruption. Non-pharmacologic interventions (NPIs) such as masking and physical distancing have formed the underpinnings of COVID-19 infection control strategies. Concomitantly, numerous jurisdictions have seen a decrease in hospitalizations for non-COVID-19 respiratory illnesses (NCRIs) such as asthma, community-acquired pneumonia, influenza, and chronic obstructive pulmonary disease relative to pre-pandemic levels. These associations give rise to a number of testable hypotheses regarding the efficacy of NPIs in reducing the substantial burden of NCRIs. Here, we review emerging perspectives on the role of NPIs in NCRI prevention with the ultimate goal of informing future research and public policy development as we move into what may be the endemic phase of the COVID-19 pandemic.
\end{abstract}

Keywords COVID-19 pandemic $\cdot$ Non-pharmacologic interventions (NPIs) $\cdot$ Masking $\cdot$ Physical distancing · Respiratory illness · Viral triggers · Chronic obstructive pulmonary disease (COPD) · Asthma · Influenza · Pneumonia . Hospitalizations

\section{Introduction}

The ongoing coronavirus disease 2019 (COVID-19) pandemic has been the source of significant global morbidity and mortality and placed an immense strain on financial and health care infrastructure. Non-pharmacologic interventions (NPIs), such as physical distancing and maskwearing, implemented to reduce COVID-19 transmission rates have been shown to effectively control disease spread

Rutvij A. Khanolkar

rutvij.khanolkar@ucalgary.ca

1 Cumming School of Medicine, University of Calgary, \#305, 2011 University Dr NW, Calgary, AB T2N 4T4, Canada

2 Department of Emergency Medicine, University of Calgary, Calgary, AB, Canada

3 University of Ottawa, Ottawa, ON, Canada

4 Division of General Internal Medicine, Department of Medicine, McMaster University, Hamilton, ON, Canada

5 Health Sciences Centre, Max Rady College of Medicine, Department of Emergency Medicine, University of Manitoba, Winnipeg, MB, Canada

6 Alberta Health Services, Calgary, AB, Canada
$[1,2]$. Concomitantly, a near-eradication of symptomatic influenza has been observed in most global jurisdictions [3, 4]. Similarly, there has been a dramatic decrease in hospitalization rates for patients with acute exacerbations of chronic obstructive pulmonary disease (COPD) and asthma, and non-COVID-19 community-acquired pneumonia (CAP) relative to pre-pandemic levels $[5,6]$. However, there have been no randomized studies to date investigating the efficacy of NPIs in preventing respiratory illnesses and it remains unknown as to which specific public health interventions may be most beneficial for prevention. The emerging literature from numerous regions worldwide raises a number of testable hypotheses regarding the effects of relatively simple infection control measures on high burden respiratory illnesses. In this article, we review the current literature on the association of NPIs with reductions in respiratory diseaserelated hospitalizations and explore potential explanations for this phenomenon. Based on these findings, we provide recommendations for future research and the development of public policy guidelines for the continued use of NPIs in high-risk populations for the purpose of controlling the perennial burden of respiratory diseases. 


\section{The natural experiment of the pandemic}

Acute and chronic respiratory diseases are among the most significant causes of morbidity and mortality worldwide [7], and are associated with a significant hospitalization rate and extended inpatient stays that negatively impact quality of life in the long-term $[6,8]$.

Throughout the pandemic, NPIs including masking, physical distancing, and lockdowns have been effective at reducing the transmission of COVID-19 [9-11]. This was recently validated in a large-scale randomized controlled trial (RCT) of 342,000 individuals in Bangladesh which reported a significant reduction in symptomatic COVID-19 among the intervention arm that received community-level mask promotion [2].

A surprising revelation from the implementation of COVID-19-related NPIs has been a concomitant decrease in the number of hospitalizations for other respiratory illnesses [5, 12-16]. Early in the pandemic, the decrease in healthcare utilization was likely contributed to by fears related to nosocomial acquisition of COVID-19, and the perception that hospital were overwhelmed and unable to accommodate nonemergent cases. This was evidenced by a global decrease in hospitalizations for many non-respiratory conditions, including congestive heart failure and diabetes $[5,15,17]$. Concomitantly, there was a decline in elective surgical admissions and procedures as operating rooms closed and surgeons re-deployed to support other clinical services $[5,6,18]$.

However, while there was a rapid rebound in the number of surgical admissions and hospitalizations for non-respiratory illnesses a few months into the pandemic [5, 17], healthcare utilization for non-COVID-19 respiratory illnesses has consistently remained low (Fig. 1). In fact, data from the Canadian Institute of Health Information (CIHI) suggests that even accounting for hospitalizations due to COVID-19, there was still a net reduction in the number of total hospitalizations related to respiratory diseases (Table 1) [6, 19]. This is unsurprising, given that NPIs are effective at stemming the spread of viral agents [9-11], which are the most commonly identified triggers of both acute respiratory illnesses and exacerbations of chronic airway diseases including COPD and asthma [20, 21]. In many ways, the institution of public health measures in response to the pandemic has served as a natural experiment into the efficacy of NPIs in preventing the spread of common respiratory viruses.

\section{Worldwide decrease in non-COVID-19 respiratory illnesses}

The decreased burden of non-COVID-19 respiratory illness has also been reported in numerous regions internationally. A recently published systematic review and meta-analysis by

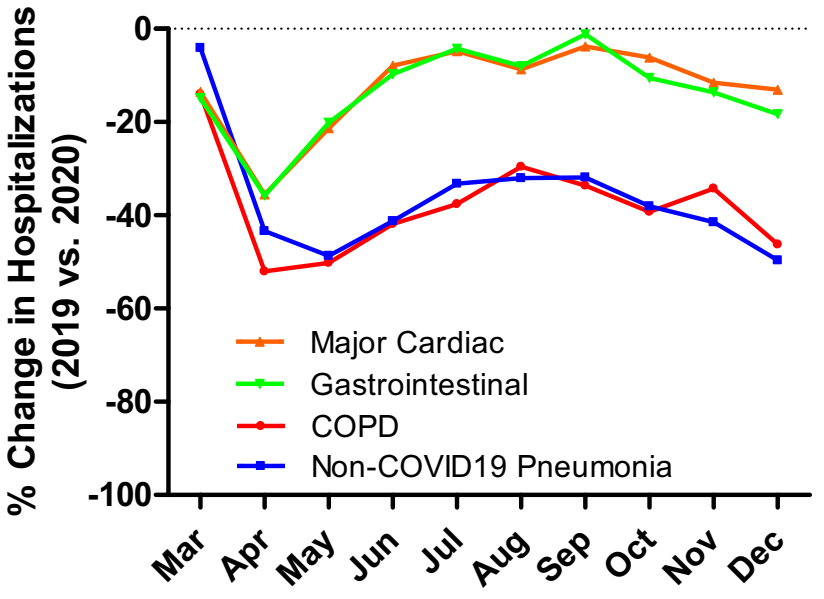

Fig. 1 Percent (\%) change in hospitalizations between the pre-pandemic (March-Dec 2019) and pandemic (March-Dec 2020) periods. Sourced from Canadian Institutes of Health Information (CIHI) reports [6]

Alqahtani et al. examined the relationship between COPD exacerbations and NPI's during the COVID-19 pandemic [12]. Thirteen studies were included, consisting of 15,677 patients from 9 countries [12], and pooled results showed a rate ratio of 0.50 [95\% confidence interval (CI): 0.44-0.57] for COPD exacerbation-related hospital admissions.

Three of the studies included in the meta-analysis specifically evaluated reduction in respiratory viral infections (RVIs) [13, 14, 22]. In a study from Singapore, the incidence rate ratio (IRR) was 0.35 , with an absolute decrease of $60 \%$ in admissions for acute exacerbations of COPD when comparing the pre-pandemic and pandemic periods [13]. Similarly, a study from Korea reported that influenza-related hospitalizations in patients with pre-existing COPD and asthma were reduced by $73 \%$ and $83 \%$, respectively [14]. Finally, a study from Hong Kong found that there was a 52\% decrease in the detection of influenza $\mathrm{A} / \mathrm{B}$ and that this corresponded with a concomitant $55 \%$ decrease in admissions for COPD exacerbations [22]. Together, the findings of these studies suggest that reducing viral infections may be linked to a reduction in COPD exacerbations [12], and that NPIs used during the pandemic period may be used to effectively reduce $\mathrm{COPD}$ exacerbations.

\section{Future directions}

As we look towards the possibility of a post-pandemic future, applying these preliminary findings on NPIs and the burden of respiratory illnesses will become increasingly important. At present, there is a paucity of literature evaluating the effects and acceptability of NPIs on disease-specific mortality with most studies from the pre-pandemic period 
Table 1 Summary of CIHI data comparing pre-pandemic and pandemic hospitalizations for common respiratory illnesses in Canada (excluding Quebec) [6, 19]

\begin{tabular}{|c|c|c|c|c|}
\hline & Cause of hospitalization & 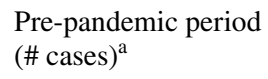 & $\begin{array}{l}\text { Pandemic period } \\
\text { (\# cases) }^{\text {b }}\end{array}$ & Difference $^{c}$ \\
\hline \multirow[t]{2}{*}{ Controls } & Major cardiac cause & 71,455 & 62,249 & $\begin{array}{l}14 \% \text { decrease } \\
P=0.003\end{array}$ \\
\hline & Gastrointestinal cause & 70,675 & 62,712 & $\begin{array}{l}13 \% \text { decrease } \\
P=0.002\end{array}$ \\
\hline \multirow[t]{2}{*}{ Non-COVID-19 respiratory illnesses } & COPD & 47,130 & 29,111 & $\begin{array}{l}38 \% \text { decrease } \\
P<0.001\end{array}$ \\
\hline & Non-COVID-19 pneumonia (NCP) & 51,310 & 32,664 & $\begin{array}{l}36 \% \text { decrease } \\
P<0.001\end{array}$ \\
\hline COVID-19 & COVID-19 & 0 & 21,912 & - \\
\hline $\begin{array}{l}\text { Total hospitalizations due to COPD, NCP } \\
\text { \& COVID-19 }\end{array}$ & - & 97,440 & 83,687 & $\begin{array}{l}14 \% \text { decrease } \\
P=0.026\end{array}$ \\
\hline
\end{tabular}

${ }^{\mathrm{a}}$ March 2019-December 2019

${ }^{\mathrm{b}}$ March 2020-December 2020 for non-COVID-19 respiratory illnesses and controls. January 2020-December 2020 for COVID-19

${ }^{\mathrm{c}} P$ value calculated by comparing the incidence rate ratios using a non-parametric paired $t$ test (Wilcoxon matched-pairs test). Analysis conducted with GraphPAD Prism software (version 5.02 for Windows, San Diego, California, USA)

having focused on interventions such as pulmonary rehabilitation, supplemental oxygen, and surgery [23]. Therefore, we provide the following recommendations on how focused studies may address current gaps in the literature.

Firstly, the substantial worldwide decrease in hospital admissions for acute respiratory illnesses [6] must be confirmed and linked to robust disease-specific mortality data. Research can be directed towards evaluating NPIs, looking at timelines for mandated measures, changes in intensity, and subsequent effects on the hospital burden of respiratory illness via a time-series analysis. A limitation of current epidemiological data is that NPIs are often considered as a whole due to the overlap in the timeline for implementation of different interventions. The use of time-series analyses will help determine whether if specific NPIs have different effects and which interventions are most effective at preventing viral transmission. Since the common viral triggers can differ based on disease type and patient demographics, this would also allow for the implementation of more targeted NPIs for different subsets of the population. Additionally, RCTs involving individuals at high risk for developing CAP or those who suffer from lung disease are needed to evaluate the efficacy of interventions such as masking on patient mortality, rates of hospitalization, and quality of life outcomes. Current evidence suggests that the efficacy of NPIs may be based more on their ability to work as a source control strategy than as personal protective equipment [24]. Therefore, randomized studies will also be required to answer the question of whether the recently demonstrated benefits of NPIs can still be attained when implemented in a selected group of patients, rather than at a population level.

Second, if there is a true effect of NPIs on the burden of non-COVID-19 respiratory illnesses, it is worthwhile considering how policies should be framed in response to this. While high quality research will help guide future evidence-based public health policies and decision making, this will take time. For example, a well-designed RCT may take several years to complete. Furthermore, as variable definitions exist for terms such as "personal protective equipment" and "medical/surgical apparatus," production standards can vary between various regions. This may pose a challenge in replicating the findings of RCTs across diverse regional and global demographics [25].

In the interim, policy-makers can evaluate current observational data and consider whether the implementation of masking measures is appropriate for patients with chronic lung diseases, those at high-risk of developing CAP, or for individuals in direct contact with them. These recommendations may be revisited and revised in the future, but voluntary measures, even on an interim basis, may help protect at-risk populations.

Finally, as with any medical intervention, it is necessary to balance the purported benefits with due consideration of any collateral risks and harms. This includes the potential dangers of masking as a mechanism for selecting out increasingly virulent viral illnesses such as those caused by respiratory syncytial virus (RSV) or influenza, as has been observed in numerous global jurisdictions following the relaxation of NPIs [26-30]. By preventing exposure, NPIs have increased the proportion of RSV-susceptible children in the population, who may be vulnerable to more serious infection if exposed at an older age when protection from maternal antibodies is no longer present. Similarly, in the case of influenza, the annual refresh of immunologic memory may serve as a barrier to the emergence of highly virulent strains from the zoonotic reservoir. Therefore, the use of 
NPIs beyond the pandemic period may have the potential to exacerbate future viral epidemics and protect some individuals while harming others. Widespread masking also has the potential to overwhelm medical waste disposal infrastructure, leading to the accumulation of masks in our landfills and oceans [31]. Additionally, if future studies reveal that more stringent NPI measures such as lockdowns are required to achieve desired efficacy, the benefit of preventing disease spread will have to be carefully weighted against the adverse impacts these measures may have on mental health and social inequity $[32,33]$

\section{Conclusion}

In this article, we have presented evidence that the measures instituted globally to control the spread of COVID-19 have unexpectedly contributed to marked and sustained reductions in hospitalizations for non-COVID-19 respiratory illnesses. Additionally, we have laid out next steps that could help us better understand which NPIs have played the most significant roles in the observed reduction of non-COVID-19 respiratory diseases. It remains unclear whether these benefits were achieved with masking interventions alone or are also reliant on more stringent physical distancing measures related to the closure of establishments and restrictions on social gatherings and travel. Evaluation of which specific measures carry the highest yield, under what conditions they are most effective, and their potential for collateral adverse effects, will be crucial in guiding policy development. Due to the limitations of the current evidence base, including the lack of studies evaluating the effect of NPIs on mortalityrelated outcomes, the consideration of patient preferences will also be important in implementation.

Given reasonable evidence from the COVID-19 pandemic, policy-makers should consider empiric public health measures for individuals at high-risk of contracting viral respiratory illnesses or suffering from adverse outcomes as a result. Such policies will likely face barriers to widespread adoption including hesitancy to embracing masking and other NPIs on a voluntary basis, the association of these measures with repressive lockdown policies, and skepticism regarding their efficacy [34]. While the use of NPIs is now variable and may only transiently persist in the early postpandemic period, it is also possible that people may continue to use them on a more routine basis as has been observed in many Asian countries.

Nonetheless, the recommendations highlighted in this analysis provide a basis for a research agenda which will aid in more conclusively determining the relative risk and benefits of selective NPI implementation on the burden of respiratory illnesses and their sequalae. We hope that relevant stakeholders will engage in elucidating the veracity and relevance of what may be the key learnings of the global COVID-19 pandemic.

Acknowledgements We thank the Canadian Institute for Health Information (CIHI) for the use of primary data on respiratory disease hospitalizations. We would like to acknowledge Satchel Krawchuk (Emergency Strategic Clinical Network) for assisting in performing the literature review for this article.

Authors contribution RAK performed the primary data analysis and constructed the figures. RAK, AT, and ESL drafted the manuscript. AA and MAP critically reviewed the manuscript for important scientific content. All authors approved the final version for publication.

\section{Declarations}

Conflict of interest The authors declare no conflicts of interest.

Human and animal rights No human and animal studies were conducted, as this article reports on a literature review and summary of previously published primary data only.

Informed consent Not applicable to this literature review article, as no human participants were involved.

\section{References}

1. Flaxman S, Mishra S, Gandy A, Unwin HJT, Mellan TA, Coupland H, Whittaker C, Zhu H, Berah T, Eaton JW, Monod M, Perez-Guzman PN, Schmit N, Cilloni L, Ainslie KEC, Baguelin M, Boonyasiri A, Boyd O, Cattarino L, Cooper LV, Cucunubá Z, Cuomo-Dannenburg G, Dighe A, Djaafara B, Dorigatti I, van Elsland SL, FitzJohn RG, Gaythorpe KAM, Geidelberg L, Grassly NC, Green WD, Hallett T, Hamlet A, Hinsley W, Jeffrey B, Knock E, Laydon DJ, Nedjati-Gilani G, Nouvellet P, Parag KV, Siveroni I, Thompson HA, Verity R, Volz E, Walters CE, Wang H, Wang Y, Watson OJ, Winskill P, Xi X, Walker PGT, Ghani AC, Donnelly CA, Riley S, Vollmer MAC, Ferguson NM, Okell LC, Bhatt S, Imperial College C-RT (2020) Estimating the effects of nonpharmaceutical interventions on COVID-19 in Europe. Nature 584:257-261. https://doi.org/10.1038/s41586-020-2405-7

2. Abaluck J, Kwong LH, Styczynski A, Haque A, Kabir MA, BatesJefferys E, Crawford E, Benjamin-Chung J, Raihan S, Rahman S, Benhachmi S, Bintee NZ, Winch PJ, Hossain M, Reza HM, Jaber AA, Momen SG, Rahman A, Banti FL, Huq TS, Luby SP, Mobarak AM (2022) Impact of community masking on COVID19: a cluster-randomized trial in Bangladesh. Science 375(6577). https://doi.org/10.1126/science.abi9069

3. Huang QS, Wood T, Jelley L, Jennings T, Jefferies S, Daniells K, Nesdale A, Dowell T, Turner N, Campbell-Stokes P, Balm M, Dobinson HC, Grant CC, James S, Aminisani N, Ralston J, Gunn W, Bocacao J, Danielewicz J, Moncrieff T, McNeill A, Lopez L, Waite B, Kiedrzynski T, Schrader H, Gray R, Cook K, Currin D, Engelbrecht C, Tapurau W, Emmerton L, Martin M, Baker MG, Taylor S, Trenholme A, Wong C, Lawrence S, McArthur C, Stanley A, Roberts S, Rahnama F, Bennett J, Mansell C, Dilcher M, Werno A, Grant J, van der Linden A, Youngblood B, Thomas PG, Webby RJ, Consortium NP (2021) Impact of the COVID-19 nonpharmaceutical interventions on influenza and other respiratory viral infections in New Zealand. Nat Commun 12(1):1001. https://doi.org/10.1038/s41467-021-21157-9 
4. Olsen SJ, Azziz-Baumgartner E, Budd AP, Brammer L, Sullivan S, Pineda RF, Cohen C, Fry AM (2020) Decreased influenza activity during the COVID-19 pandemic-United States, Australia, Chile, and South Africa, 2020. MMWR Morb Mortal Wkly Rep 69:1305-1309. https://doi.org/10.15585/mmwr.mm6937a6

5. Rennert-May E, Leal J, Thanh NX, Lang E, Dowling S, Manns B, Wasylak T, Ronksley PE (2021) The impact of COVID-19 on hospital admissions and emergency department visits: a populationbased study. PLoS ONE 16:e0252441. https://doi.org/10.1371/ journal.pone.0252441

6. Canadian Institute for Health Information (2021) Top reasons for admission, March to December 2020. Accessed June 15th, 2021. https://www.cihi.ca/en/covid-19-resources/impact-of-covid-19on-canadas-health-care-systems/covid-19s-effect-on-hospital.

7. Table 13-10-0394-01 Leading causes of death, total population, by age group. Accessed August 7th, 2021. https://doi.org/10. 25318/1310039401-eng.

8. Satia I, Cusack R, Greene JM, O’Byrne PM, Killian KJ, Johnston $N$ (2020) Prevalence and contribution of respiratory viruses in the community to rates of emergency department visits and hospitalizations with respiratory tract infections, chronic obstructive pulmonary disease and asthma. PLoS ONE 15:e0228544. https:// doi.org/10.1371/journal.pone.0228544

9. Wiersinga WJ, Rhodes A, Cheng AC, Peacock SJ, Prescott HC (2020) Pathophysiology, transmission, diagnosis, and treatment of coronavirus disease 2019 (COVID-19): a review. JAMA 324:782793. https://doi.org/10.1001/jama.2020.12839

10. Walker PGT, Whittaker C, Watson OJ, Baguelin M, Winskill P, Hamlet A, Djafaara BA, Cucunubá Z, Olivera Mesa D, Green W, Thompson H, Nayagam S, Ainslie KEC, Bhatia S, Bhatt S, Boonyasiri A, Boyd O, Brazeau NF, Cattarino L, Cuomo-Dannenburg G, Dighe A, Donnelly CA, Dorigatti I, van Elsland SL, FitzJohn R, Fu H, Gaythorpe KAM, Geidelberg L, Grassly N, Haw D, Hayes S, Hinsley W, Imai N, Jorgensen D, Knock E, Laydon D, Mishra S, Nedjati-Gilani G, Okell LC, Unwin HJ, Verity R, Vollmer M, Walters CE, Wang H, Wang Y, Xi X, Lalloo DG, Ferguson NM, Ghani AC (2020) The impact of COVID-19 and strategies for mitigation and suppression in low- and middleincome countries. Science 369:413-422. https://doi.org/10.1126/ science.abc0035

11. Prem K, Liu Y, Russell TW, Kucharski AJ, Eggo RM, Davies N, Jit M, Klepac P (2020) The effect of control strategies to reduce social mixing on outcomes of the COVID-19 epidemic in Wuhan, China: a modelling study. Lancet Public Health 5:e261-e270. https://doi.org/10.1016/s2468-2667(20)30073-6

12. Alqahtani JS, Oyelade T, Aldhahir AM, Mendes RG, Alghamdi SM, Miravitlles M, Mandal S, Hurst JR (2021) Reduction in hospitalised COPD exacerbations during COVID-19: a systematic review and meta-analysis. PLoS ONE 16:e0255659-e0255659. https://doi.org/10.1371/journal.pone.0255659

13. Tan JY, Conceicao EP, Wee LE, Sim XYJ, Venkatachalam I (2021) COVID-19 public health measures: a reduction in hospital admissions for COPD exacerbations. Thorax 76:512-513. https:// doi.org/10.1136/thoraxjnl-2020-216083

14. Huh K, Kim YE, Ji W, Kim DW, Lee EJ, Kim JH, Kang JM, Jung J (2021) Decrease in hospital admissions for respiratory diseases during the COVID-19 pandemic: a nationwide claims study. Tho$\operatorname{rax}$ 76:939-941. https://doi.org/10.1136/thoraxjnl-2020-216526

15. Ullrich A, Schranz M, Rexroth U, Hamouda O, Schaade L, Diercke M, Boender TS (2021) Impact of the COVID-19 pandemic and associated non-pharmaceutical interventions on other notifiable infectious diseases in Germany: an analysis of national surveillance data during week 1-2016-week 32-2020. Lancet Reg Health Eur. https://doi.org/10.1016/j.lanepe.2021.100103

16. Oh D-Y, Buda S, Biere B, Reiche J, Schlosser F, Duwe S, Wedde M, von Kleist M, Mielke M, Wolff T, Dürrwald R (2021) Trends in respiratory virus circulation following COVID-19-targeted nonpharmaceutical interventions in Germany, January-September 2020: analysis of national surveillance data. Lancet Reg Health Eur. https://doi.org/10.1016/j.lanepe.2021.100112

17. Birkmeyer JD, Barnato A, Birkmeyer N, Bessler R, Skinner J (2020) The impact of the COVID-19 pandemic on hospital admissions in the United States. Health Aff 39:2010-2017. https://doi.org/10.1377/hlthaff.2020.00980

18. Collaborative CO (2020) Elective surgery cancellations due to the COVID-19 pandemic: global predictive modelling to inform surgical recovery plans. Br J Surg 107:1440-1449. https://doi. org/10.1002/bjs.11746

19. Canadian Institute for Health Information (2021) COVID-19 Hospitalization and Emergency Department Statistics, 20192020 and 2020-2021. Accessed August 15th, 2021. https:// www.cihi.ca/en/covid-19-hospitalization-and-emergency-depar tment-statistics

20. Vestbo J, Hurd SS, Agustí AG, Jones PW, Vogelmeier C, Anzueto A, Barnes PJ, Fabbri LM, Martinez FJ, Nishimura M, Stockley RA, Sin DD, Rodriguez-Roisin R (2013) Global strategy for the diagnosis, management, and prevention of chronic obstructive pulmonary disease: GOLD executive summary. Am J Respir Crit Care Med 187:347-365. https://doi.org/10.1164/rccm. 201204-0596PP

21. Johnston NW, Sears MR (2006) Asthma exacerbations. 1: epidemiology. Thorax 61:722-728. https://doi.org/10.1136/thx.2005. 045161

22. Chan KPF, Ma TF, Kwok WC, Leung JKC, Chiang KY, Ho JCM, Lam DCL, Tam TCC, Ip MSM, Ho PL (2020) Significant reduction in hospital admissions for acute exacerbation of chronic obstructive pulmonary disease in Hong Kong during coronavirus disease 2019 pandemic. Respir Med 171:106085. https://doi.org/ 10.1016/j.rmed.2020.106085

23. Halpin DM, Miravitlles M, Metzdorf N, Celli B (2017) Impact and prevention of severe exacerbations of COPD: a review of the evidence. Int J Chron Obstruct Pulmon Dis 12:2891-2908. https:// doi.org/10.2147/copd.s139470

24. Howard J, Huang A, Li Z, Tufekci Z, Zdimal V, van der Westhuizen HM, von Delft A, Price A, Fridman L, Tang LH, Tang V, Watson GL, Bax CE, Shaikh R, Questier F, Hernandez D, Chu LF, Ramirez CM, Rimoin AW (2021) An evidence review of face masks against COVID-19. Proc Natl Acad Sci USA. https://doi. org/10.1073/pnas.2014564118

25. Rubio-Romero JC, Pardo-Ferreira MDC, Torrecilla-García JA, Calero-Castro S (2020) Disposable masks: disinfection and sterilization for reuse, and non-certified manufacturing, in the face of shortages during the COVID-19 pandemic. Saf Sci 129:104830. https://doi.org/10.1016/j.ssci.2020.104830

26. Baker RE, Park SW, Yang W, Vecchi GA, Metcalf CJE, Grenfell BT (2020) The impact of COVID-19 nonpharmaceutical interventions on the future dynamics of endemic infections. Proc Natl Acad Sci USA 117:30547-30553. https://doi.org/10.1073/pnas. 2013182117

27. Foley DA, Yeoh DK, Minney-Smith CA, Martin AC, Mace AO, Sikazwe CT, Le H, Levy A, Moore HC, Blyth CC (2021) The interseasonal resurgence of respiratory syncytial virus in Australian children following the reduction of coronavirus disease 2019-related public health measures. Clin Infec Dis. https://doi. org/10.1093/cid/ciaa1906

28. National flu and COVID-19 surveillance report: rsv admissions. Accessed August 27th, 2021. https://www.gov.uk/gover $\mathrm{nment} /$ statistics/national-flu-and-covid-19-surveillance-repor ts-2021-to-2022-season.

29. Agha R, Avner JR (2021) Delayed seasonal RSV surge observed during the COVID-19 pandemic. Pediatrics 148:e2021052089. https://doi.org/10.1542/peds.2021-052089 
30. Ujiie M, Tsuzuki S, Nakamoto T, Iwamoto N (2021) Resurgence of respiratory syncytial virus infections during COVID-19 pandemic, Tokyo. Jpn Emerg Infect Dis 27:2969-2970. https://doi. org/10.3201/eid2711.211565

31. Dharmaraj S, Ashokkumar V, Hariharan S, Manibharathi A, Show PL, Chong CT, Ngamcharussrivichai C (2021) The COVID-19 pandemic face mask waste: a blooming threat to the marine environment. Chemosphere 272:129601. https://doi.org/10.1016/j. chemosphere.2021.129601

32. Niedzwiedz CL, Green MJ, Benzeval M, Campbell D, Craig P, Demou E, Leyland A, Pearce A, Thomson R, Whitley E, Katikireddi SV (2021) Mental health and health behaviours before and during the initial phase of the COVID-19 lockdown: longitudinal analyses of the UK household longitudinal study. J Epidemiol Community Health 75:224. https://doi.org/10.1136/ jech-2020-215060
33. Schippers MC (2020) For the greater good? The devastating ripple effects of the Covid-19 crisis. Front Psychol. https://doi.org/10. 3389/fpsyg.2020.577740

34. Taylor S, Asmundson GJG (2021) Negative attitudes about facemasks during the COVID-19 pandemic: the dual importance of perceived ineffectiveness and psychological reactance. PLoS ONE 16:e246317. https://doi.org/10.1371/journal.pone.0246317

Publisher's Note Springer Nature remains neutral with regard to jurisdictional claims in published maps and institutional affiliations. 